\title{
Enhanced computed tomography showing dissection-like features in an extracorporeal membrane oxygenation-supported patient with no cardiac output: Can acute type A aortic dissection be excluded?
}

\author{
Tomohiro Mizuno, MD, PhD, Keiji Oi, MD, PhD, and Hirokuni Arai, MD, PhD
}

\footnotetext{
From the Department of Cardiovascular Surgery, Graduate School of Medical and Dental Science, Tokyo Medical and Dental University, Tokyo, Japan.

Disclosures: Authors have nothing to disclose with regard to commercial support.

No grant support, fund support, or indirect financial relationship from any commercial entity was used to support this study.

Received for publication Aug 8, 2017; revisions received Oct 9, 2017; accepted for publication Oct 30, 2017.

Address for reprints: Tomohiro Mizuno, MD, PhD, Tokyo Medical and Dental University, Graduate School of Medical and Dental Science, Department of Cardiovascular Surgery, 1-5-45, Yushima, Bunkyo-ku, Tokyo 113-8519, Japan (E-mail: mizuno.cvsg@tmd.ac.jp).

J Thorac Cardiovasc Surg 2018;155:1637-9

$0022-5223 / \$ 36.00$

Copyright (C) 2017 by The American Association for Thoracic Surgery

https://doi.org/10.1016/j.jtcvs.2017.10.126
}

- Video clip is available online.

We encountered a patient with misleading computed tomographic (CT) findings that resembled those of acute type A aortic dissection (AD).

A 60-year-old man with pulseless electrical activity was transferred to our emergency department. Extracorporeal membrane oxygenation (ECMO) was quickly initiated. The patient's echocardiogram showed severely impaired left ventricular function, with no cardiac output from the left ventricle. After the initiation of ECMO, the CT revealed

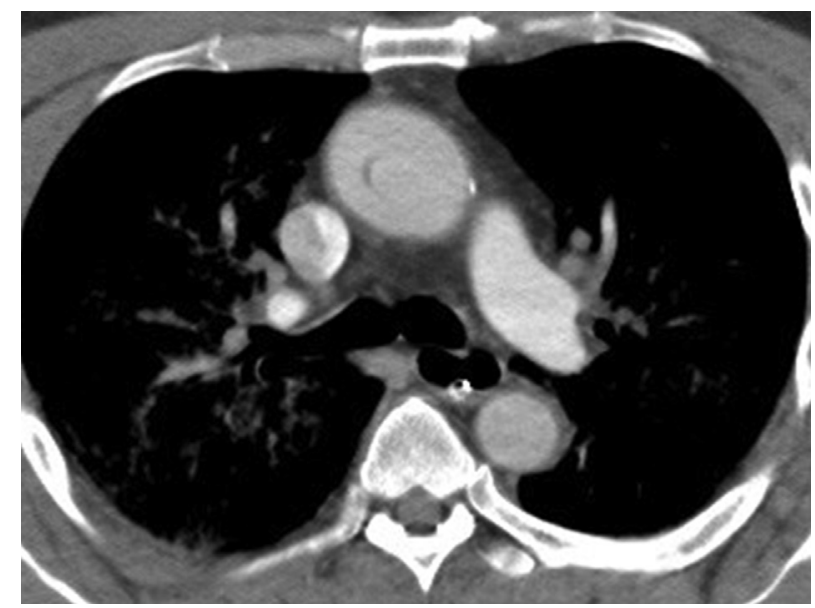

FIGURE 1. Computed tomography showing dissectionlike features. The intimal flap-like septum is also shown.

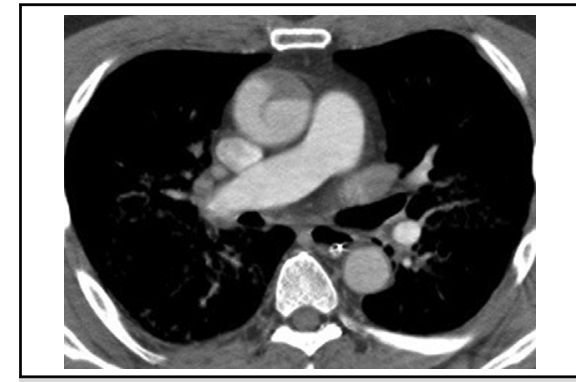

Computed tomographic findings that resemble acute type A aortic dissection.

Central Message
Aortic dissection-like computed tomography
findings in a patient with mechanical circula-
tory support after left coronary ostial occlusion
can mislead clinicians when determining treat-
ment strategy.

See Editorial Commentary page 1640.

that the mid to distal portion of the ascending aorta and proximal aortic arch resembled those of acute type A AD (Figure 1). We made a diagnosis of acute type A AD with

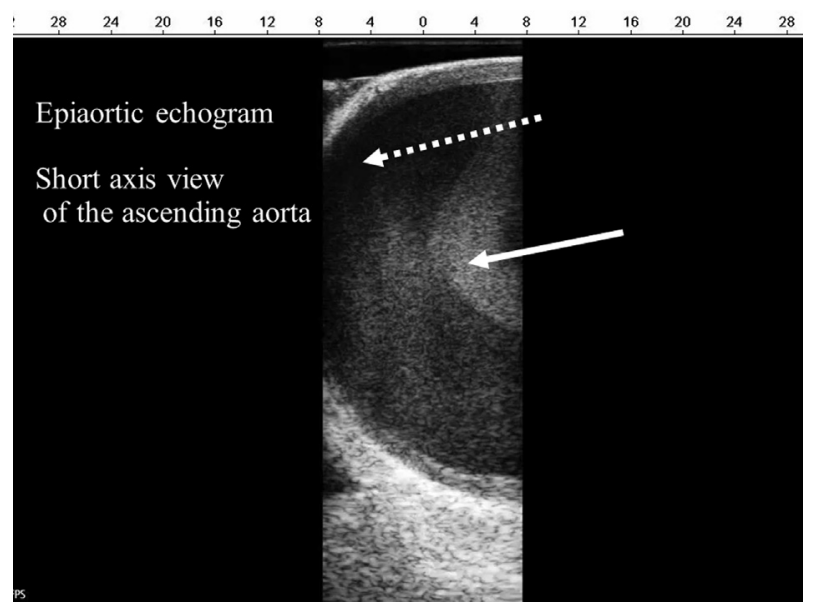

FIGURE 2. Epiaortic echography reveals slow blood flow to the patent right coronary artery and arch vessels from the retrograde perfusion of extracorporeal membrane oxygenation in the greater curvature of the aorta (dotted arrow) and blood stagnation in the lesser curvature (white arrow). 


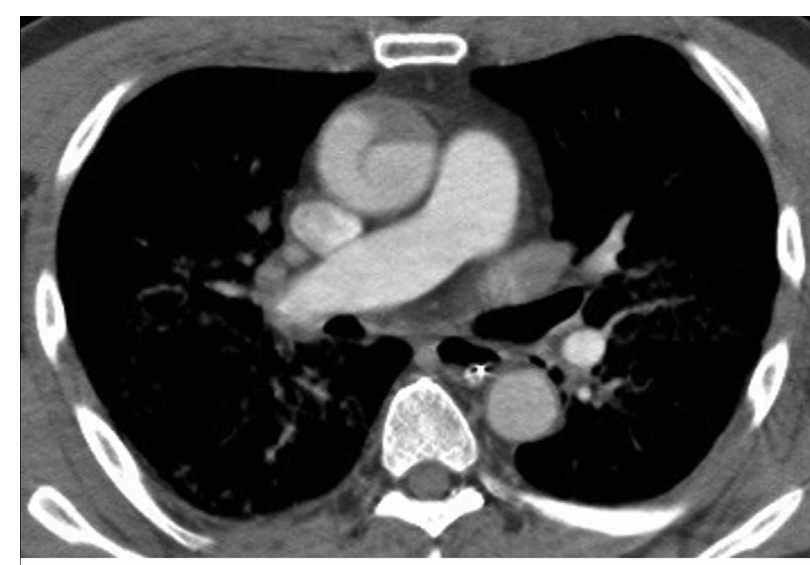

The CT findings resembled those of acute type A aortic dissection.

VIDEO 1. The video shows intraoperative epiaortic echography. Two layers of blood flow can be seen; one slows blood flow to the patent right coronary artery and arch vessels, and the other shows stagnant blood from the retrograde perfusion of percutaneous cardiopulmonary support. CT, Computed tomography. Video available at: http://www.jtcvsonline.org/article/S0022-5223(17)32474-1/fulltext.

ostial occlusion of the left main coronary artery and planned emergency replacement of the ascending aorta, coronary artery bypass grafting, and initiation of central ECMO or implantation of a left ventricular assist device.

Acute AD was not, however, observed under direct vision. Preoperative transesophageal echocardiography (TEE) could not exclude AD because of the "blind spot" of TEE. Epiaortic echography revealed 2 blood flow layers in the ascending aorta and aortic arch. The support flow from the femoral artery stagnated at the aortic valve, because no blood emerged from the nonfunctioning left ventricle (Figure 2 and Video 1). The misleading findings on CT may be attributable to blood stagnation. We performed coronary artery bypass grafting and left ventricular assist device implantation. The patient is currently alive with left ventricular assist device support. We recognized negative $\mathrm{CT}$ findings inconsistent with acute $\mathrm{AD}$, such as an intact sinus of Valsalva and an intimal flap-like low-density borderline in the aortic arch, which lacked continuity with both the proximal and distal sides, and positive findings for acute myocardial infarction, such as severe calcification of the left coronary artery (Figures 3 and 4$).{ }^{1,2}$ Although the visualization of the distal ascending aorta and aortic arch is impaired relative to $\mathrm{CT}$, the diagnostic sensitivity of TEE for $\mathrm{AD}$ is almost $100 \%$. Even in patients in hemodynamically unstable condition, TEE can be performed in an operating room. Additional multimodality imaging including modified TEE thus could have helped to avoid a false-positive diagnosis in a patient on ECMO. ${ }^{3}$

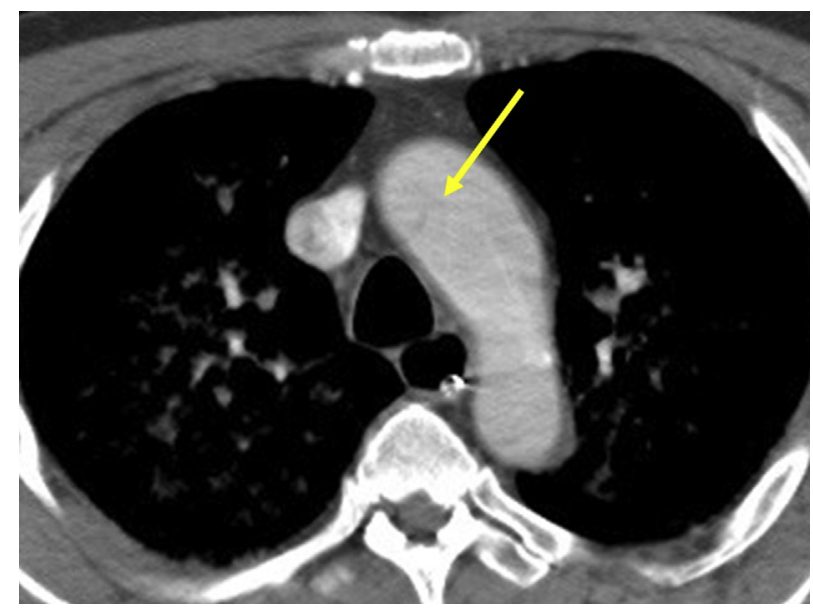

FIGURE 3. Negative finding inconsistent with acute aortic dissection. The intimal flap-like borderline lacks continuity with both the proximal and distal side (yellow arrow). 


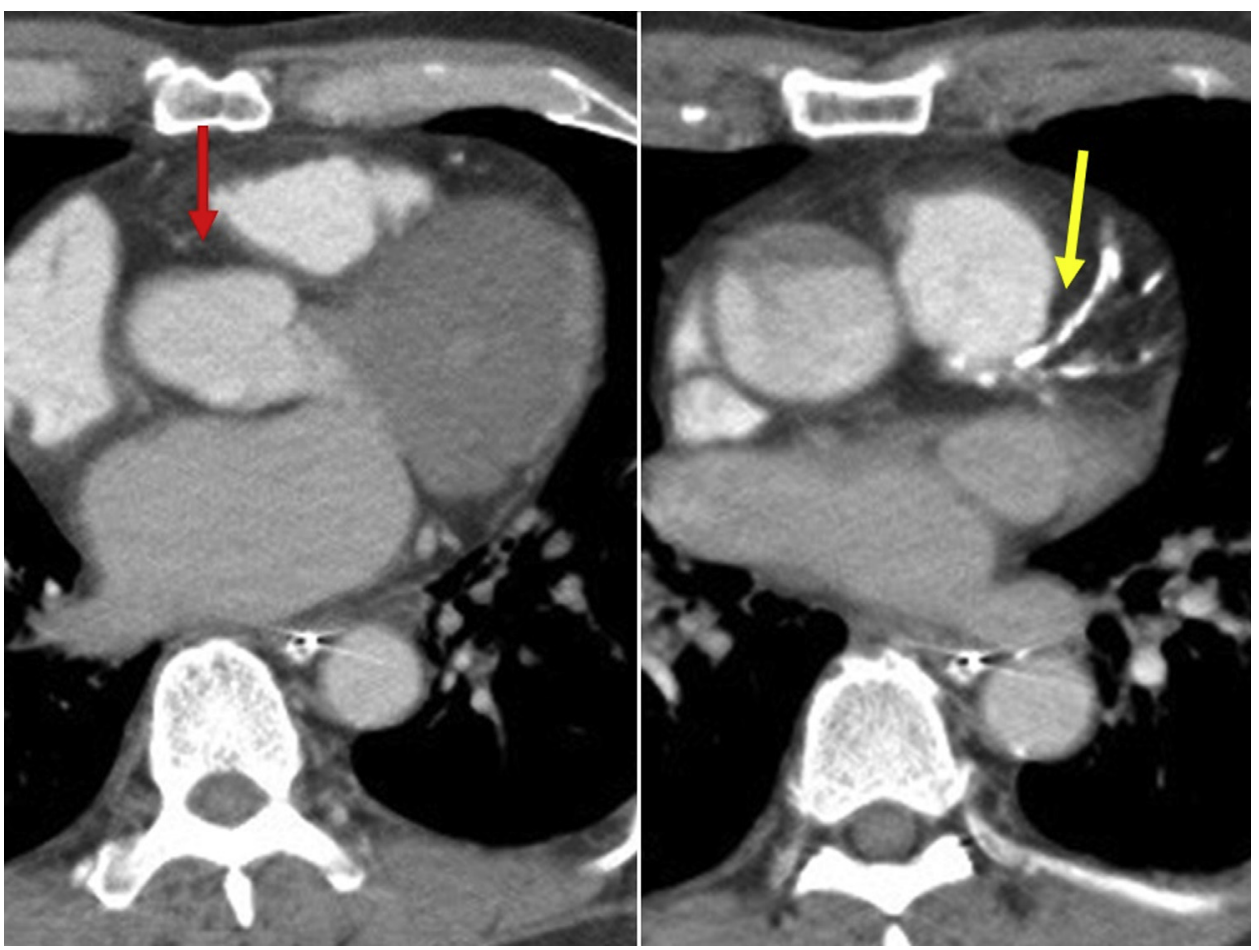

FIGURE 4. Positive computed tomographic findings of acute myocardial infarction. The intact aortic root (left, red arrow) and severe calcification of the left coronary artery (right, yellow arrow) are shown.

\section{References}

1. Willoteaux S, Lions C, Gaxotte V, Negaiwi Z, Beregi JP. Imaging of aortic dissection by helical computed tomography (CT). Eur Radiol. 2004;14:1999-2008.

2. Kapustin AJ, Litt HI. Diagnostic imaging for aortic dissection. Semin Thorac Cardiovasc Surg. 2005;17:214-23.
3. Jansen Klomp WW, Peelen LM, Brandon Bravo Bruinsma GJ, Van' Hof AW, Grandjean JG, Nierich AP. Modified transesophageal echocardiography of the dissected thoracic aorta; a novel diagnostic approach. Car diovasc Ultrasound. 2016;14:28. Erratum in: Cardiovasc Ultrasound. 2016;14:39. 